\section{Commentary: Success lies in attention to details when performing open repair of thoracoabdominal aneurysms}

\author{
Christopher Lau, MD, and Leonard N. Girardi, MD
}

Chronic thoracoabdominal aortic aneurysm (TAAA) with dissection presents an interesting and complex challenge for surgeons owing to the high degree of variability in the anatomy of the dissected aorta and its branch vessels. Although some success has been made with endovascular interventions in a subset of highly selected patients, the applicability of endovascular solutions remains limited by anatomy. The locations of branch vessels, the primary tear, downstream fenestrations, and landing zones all need to be considered carefully. Even with successful initial repair, the need for reintervention exceeds $30 \%,{ }^{1,2}$ due in part to the significantly more limited aortic remodeling seen in chronic dissection compared with acute dissection cases, owing to the relatively stiff intimal flap. ${ }^{3}$ As such, open repair has remained the gold standard, the most durable surgical approach to chronic thoracoabdominal dissecting aneurysms. In this issue of the Journal, Hong and Coselli ${ }^{4}$ present their operative and perioperative techniques for achieving optimal outcomes with open repair.

As seen in many areas of subspecialty surgery, the use of the appropriate surgical technique may achieve good results, but meticulous attention to the minute details of the procedure and perioperative care is how one achieves excellent outcomes. This is truer for an extent II TAAA repair than for any other procedure, owing to its profound effect

From the Department of Cardiothoracic Surgery, Weill Cornell Medicine, New York, NY.

Disclosures: The authors reported no conflicts of interest.

The Journal policy requires editors and reviewers to disclose conflicts of interest and to decline handling or reviewing manuscripts for which they may have a conflict of interest. The editors and reviewers of this article have no conflicts of interest.

Received for publication Jan 25, 2021; revisions received Jan 25, 2021; accepted for publication Jan 25, 2021; available ahead of print Jan 30, 2021.

Address for reprints: Leonard N. Girardi, MD, Department of Cardiothoracic Surgery, Weill Cornell Medicine, 525 East 68th St, M-404, New York, NY 10065 (E-mail: lngirard@med.cornell.edu).

JTCVS Techniques 2021;10:24-5

2666-2507

Copyright $@ 2021$ The Authors. Published by Elsevier Inc. on behalf of The American Association for Thoracic Surgery. This is an open access article under the CC BY-NCND license (http://creativecommons.org/licenses/by-nc-nd/4.0/).

https://doi.org/10.1016/j.xjtc.2021.01.035

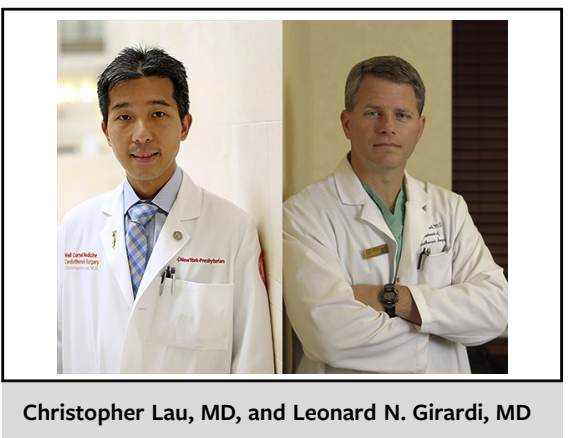

\section{CENTRAL MESSAGE \\ Successful repair of thoracoab- \\ dominal aortic aneurysms re- \\ quires meticulous attention to all \\ aspects of the operative pro- \\ cedure and perioperative care.}

on the circulation and the need to maintain excellent hemodynamics and blood flow to prevent devastating complications, such as spinal cord injury and end-organ ischemia. In addition, although any individual management decision may contribute a fractionally small amount to improving outcomes, the additive effect of these small decisions is measurably improved outcomes.

As Hong and Coselli describe in detail, the process begins with preoperative preparation by carefully assessing the imaging data, which allows for many decisions to be made before arrival to the operating room. Since this is an operation in which speed is important, decreasing the number of intraoperative decisions will be beneficial. In the operating room, the importance of the interactions of management decisions becomes more apparent; for example, our group and the authors do not monitor motor-evoked potentials. In addition, the authors describe their spinal drain management, but ours uses slightly more aggressive drainage of up to $20 \mathrm{~mL} / \mathrm{h}$ to keep the cerebrospinal fluid pressure below $12 \mathrm{~mm} \mathrm{Hg}$. Moreover, the authors use left heart bypass with cold renal and blood visceral perfusion for extent II TAAA, but other groups may use different perfusion techniques, such as circulatory arrest. Finally, the order of progression in the repair procedure is designed to preserve as much vital blood flow as possible at each step of the case: initiation of left heart bypass, cross-clamp application, proximal anastomosis, left heart bypass discontinuation, renal/visceral perfusion, intercostal reimplantation, distal anastomosis, and finally visceral reimplantation. 
Although individual aspects of TAAA repair may differ between groups, what is important is how those individual decisions interact with each other to produce a positive outcome. As evidenced by their complete series, ${ }^{5}$ Dr Coselli's group has found a method that works for them. Clearly, every minute detail of the operation has been carefully thought out and perfected over time.

\section{References}

1. Arnaoutakis DJ, Khan TA, Scali ST, Neal D, Giles KA, Cooper MA, et al. Remodeling, reintervention, and survival after endovascular repair of chronic type B dissection. Ann Thorac Surg. September 20, 2020 [Epub ahead of print].

2. Hellgren T, Kuzniar M, Wanhainen A, Steuer J, Mani K. Clinical and morphologic outcomes of endovascular repair for subacute and chronic type B aortic dissection. Ann Vasc Surg. September 2, 2020 [Epub ahead of print].

3. Dohle D-S, Laverne T, Bavaria J, Savino D, Vallabhajosyula P, Szeto WY, et al. Aortic remodelling after thoracic endovascular aortic repair in acute and chronic type B aortic dissections. Eur J Cardiothorac Surg. 2020;58: 730-7.

4. Hong JC, Coselli JS. Open repair remains the gold standard. J Thorac Cardiovasc Surg Tech. 2021;10:16-23.

5. Coselli JS, LeMaire SA, Preventza O, de la Cruz KI, Cooley DA, Price MD, et al Outcomes of 3309 thoracoabdominal aortic aneurysm repairs. J Thorac Cardiovasc Surg. 2016;151:1323-37. 